\title{
TRADICIÓN ORAL
}

\section{EL NARRAR EN ASHÁNINKA: LA ORALIDAD DEL RÍO Y ESCUELA}

\author{
Pablo Jacinto Santos ${ }^{1}$ \\ Universidad Nacional Mayor de San Marcos-EILA \\ pablo.jacinto@unmsm.edu.pe \\ (1) https://orcid.org/0000-0003-1202-6171
}

\section{Resumen}

El presente estudio aborda la lógica continuum del relato oral en la narrativa asháninka. Actualmente evidenciamos que el narrar en asháninka es una preferencia que contribuye reconocer los usos discursivos que tienen las narraciones asháninkas que continúan presentes difundiéndose como tradición oral en pleno siglo XXI y su relación con el nivel escrito. Nuestra pesquisa centra su atención en la narrativa asháninka, en las formas de la superestructura, macroestructura y microestructura que dan los parámetros de análisis sobre cómo se inician y cómo se terminan los relatos míticos. Finalmente, presentamos un modelo de estructura escrita que analiza diversos relatos míticos que fueron recopilados por autores indígenas y autores no indígenas ribereños.

Palabras claves: Narrativa asháninka; Escuela; EIB; Relatos míticos

1 Este trabajo corresponde a las pesquisas del grupo de investigación EILA-UNMSM, proyectos "Narrativa asháninka y escuela" y "El narrar en asháninka. La oralidad del río y escuela” financiados por la VRIP-UNMSM. 


\section{Summary}

This study addresses the continuum logic of the oral story in Asháninka narrative. We show that storytelling in Asháninka is a preference that contributes to recognizing the discursive uses of Asháninka narratives that continue to be used as oral tradition in the XXI century and its relationship to the written form. Our research focuses on Asháninka narrative, on the forms of superstructure, macrostructure and microstructure that give us the parameters for analysis on how mythical stories are initiated and ended. Finally, we present a model of written structure that analyzes various mythical stories that were compiled by indigenous authors and non-indigenous riverine authors.

Keywords: Asháninka narrative; Schools; IBE; Mythical stories

\section{Introducción}

A nivel oral, la lógica continuum del relato en el pueblo asháninka se da en el tiempo mítico que se conoce como peerani, pairani o peirani (antes, anteriormente, antiguamente, hace tiempo). En el discurso asháninka, el relato mítico es un continuum o continuación lógica de eventos o circunstancias de interés del ser en la unidad de un mismo acto narrado. Postulo, que, donde no hay una secuencia continua hay descripción, efusión lírica (poema) y deducción. Asimismo, donde no hay integridad en la unidad de la acción hay proceso de cronología (serie de hechos, datos, sucesos, etc., por orden de fechas). Una explicación más afín según el ciclo narrativo de la lógica continuum del relato se puede ejemplificar como "para que exista relato" debe darse los siguientes elementos: la integración en la unidad de una acción, implicación de interés humano y sucesión de acontecimientos. En el tiempo presente, en los relatos míticos se pueden escuchar y observar cómo la temporalidad, los contenidos y la estructura de relatos míticos inician con Meeka o Iroñaaka que significa "Ahora, hoy, en la actualidad, actualmente, en este momento, etc". (MINEDU 2000: 138).

La oralidad del pueblo asháninka en la Selva Central está fundada en las costumbres y manifestaciones socioculturales como: los cantos, los cuentos, las historias, las danzas, los bailes, la caza y pesca entre otros, que expresan la vivencia cotidiana y la memoria colectiva (Espino 2015; Vírhuez 2010). En efecto, estas manifestaciones a nivel de discurso se han transmitido de generación en generación y se siguen transmitiendo hasta la actualidad en forma oral de padres a hijos (Anderson 2002). No solo nos interesa cómo se 
trasmiten oralmente, sino las formas de la estructura lingüística asháninka que se emplea en el modelo de la superestructura, macroestructura y microestructura, es decir, cómo se inician y cómo se terminan los relatos míticos: desde un estado atemporal (hace tiempo), luego en el pasado (hace poco tiempo) y hasta cercanos años detrás del presente. Este proceso advierte que el pueblo asháninka no tuvo una escritura propia que permitiera documentar las manifestaciones culturales que se observan ahora; todo el contenido material e inmaterial era a través de imágenes simbólicas representativas o iconografías o como se dijo, la trasmisión oral. Por lo que, indago cómo la persona asháninka era capaz de construir su propia forma de aprendizaje guiado y aprendizaje no guiado en su contexto (Anderson 2002: 154). Además, la persona (abuelo, sabio, anciano) retenía los diversos conocimientos orales por mucho tiempo sobre la transmisión de saberes que aprendían de los ancestros (bisabuelos, tatarabuelos) que los enseñaban a través del discurso narrativo oral (Espino 2015). Los elementos a quienes narraban fueron a los seres animados e inanimados del bosque, a los animales, a las plantas, a las cumbres o montes, a los peces, a las chicharras, a los grillos, etc., cuyos contenidos nos dan una explicación de enseñanza guiadano guiada (mirando-haciendo = teórico-práctico) que evidencian la pedagogía visual de imágenes contextualizadas e iconográficas. Las narraciones orales de relatos míticos que se escucha cotidianamente de los mentores nativos guardan enseñanzas, saberes y conocimientos que se relacionan con los valores de las normas de convivencia cultural (Espinoza 2014).

\section{Antecedentes}

La narrativa oral asháninka cuenta con escasísimos repositorios físicos y virtuales para realizar consultas académicas y se puede afirmar que los registros orales (grabaciones de audios, videos, audiovideos, etc.) a la fecha no han sido trabajados por los propios integrantes de la cultura. Conviene subrayar, a pesar de la escasa producción académica sobre la narrativa oral del pueblo asháninka, autores ajenos a la cultura desarrollaron parte de esta producción escrita. La producción de la narrativa oral y escrita viene consignada por autores ribereños ajenos a la lengua asháninka hizo que se implementen repositorios físicos y virtuales en diferentes espacios de las instituciones no gubernamentales: Instituto del Bien Común (IBC-PERÚ), Centro Amazónico de Antropología y Aplicación Práctica (CAAAP), CARE-PERU, Instituto Lingüístico de Verano (ILV PERÚ), CHIRAPAQ, AIDESEP, etc. 
Al hacer una revisión bibliográfica de los documentos escritos en español y otras veces de carácter bilingüe asháninka-español/ashéninka-español, hemos encontrado contenidos de relatos míticos o tradiciones orales de orígenes, contenidos de tradiciones de transformaciones míticas, cada uno con su propio estilo de relatar o narrar. Las instituciones no gubernamentales públicas y privadas que trabajan con el grupo asháninka desde hace más de 40 años en diversos temas de (salud, educación, territorio, justicia indígena, turismo, etc.) mantienen el mismo contenido de la tradición oral que obtuvieron en su momento cuando visitaron e ingresaron a campo en las comunidades nativas, pero toda esa información de la narrativa oral y escrita en asháninka se concentra en Lima. En consecuencia, en los pueblos indígenas, en especial en los pueblos asháninka y ashéninka, no existe un repositorio virtual o físico, ni museos etnográficos (en la misma zona) que se pueda consultar, reflexionar e incorporar para la didáctica indígena.

En la década pasada de (2000-2010) o antes, se ha desarrollado investigaciones en torno a la cultura y literatura asháninka que nos han ayudado a re-identificar contenidos narrativos que nos ayuden a constatar las diversas formas de narrar: su inicio (¿Cómo se inicia la narración?) o finaliza (¿Cómo se termina la narración?). Podemos mencionar algunos antecedentes: a partir del siglo XX se realizaron proyectos autónomos de la narrativa oral asháninka. La gran mayoría de los relatos proceden de los pueblos indígenas amazónicos, estos se publican en español dejando de lado el valor de la escritura en la lengua originaria. Por ello, Solari (2019) en su tesis de investigación sobre la etnosemántica de los colores en la lengua asháninka, presenta ejemplos de la forma narrativa solo de la versión española del cuento narrado. El contenido es como sigue: "Antiguamente había una persona que comía a la gente y esa persona se ha convertido en un ave llamado Tisoni" (2019: 233). Finalmente, para el caso de las frases de salida o cómo termina el relato, en el relato mítico no se ve esos contenidos, está incompleto.

Los autores Vírhuez, Yapo y Yanes (2014) en su libro Seres fantásticos del Perú, recopilaron diferentes cuentos de la narrativa oral de los pueblos andinos y amazónicos que presenta algo en particular: el caso de los ashéninka. Sobre cómo se inicia el narrar y nos dan esta frase de inicio en español: "Entre los ashéninka hay un cerro llamado Korintoni, donde habita una antigua fiera que muy pocos han logrado ver". Revisando el contenido de finalización, encontramos que concluyen la narración oral con esta frase de salida: "Familias enteras han 
desaparecido por su causa, y aun ahora la gente tiene miedo de andar por los montes de Korintoni, territorio de la temible Korinto" (2014: 43).

Jacinto Santos (2009), presenta en su tesis de la cultura asháninka algunas frases en español de cómo se inician los relatos que se narran. Para ilustrar, "En otro tiempo anterior, Oitasatsi y Tasorentsi invitaron a todas las divinidades del cielo para celebrar un gran casamiento de su descendencia en el espacio territorial de la constelación Orión”. Esta narración oral tiene contenido mítico que se puede advertir en algunas frases finales de cómo terminan las narraciones míticas: "Cada cierto tiempo los hijos retornaban al cielo para hablar con sus padres Luna Ash y Aah y luego se iban a hablar con el dador de la vida, Oitasatsi y Tasorentsi, pidiéndole poder y protección" (2009: 57-58).

Toro Calvo (2007) como se citó en Biagio y Pereira (2007) escritor amazónico e investigador de la Literatura Peruana, presenta la forma de narrar en el pueblo asháninka la versión española del Mito de Pachakamaite. Este contenido tiene a "Pachakamaite como Pawa ('padre y dios'), vive río abajo. Él no es virakocha, no es chori. Es el hijo del dios Sol, y Mamántziki es su señora esposa”. El tema de estudio es de gran relevancia porque que nos acerca a los mitos de origen en donde Toro Calvo se explaya al narrarlo: "Hablan que mencionan, que los pagan, pero es pura invención. Su 'patrón' nos envía a nosotros los asháninkas" (2007: 63-65).

Yangali Vargas (2016), en su libro Entegonía de los pueblos originarios de la Selva Central peruana en su literatura oral muestra contenidos culturales de recopilación bibliográfica basada en diversos autores que le antecedieron. Él nos presenta su trabajo literario en la forma narrativa del español, mas no incorpora la versión asháninka. $\mathrm{El}$ contenido mítico de la obra nos permite exhibirlo de la forma siguiente: "Cuando recién se había formado la tierra, hubo aquí un asháninka que se llamaba Avíreri. Era un paisano viejo que llevaba a su nieto cargado sobre sus hombros". La finalización de la narración de este relato mítico menciona: "Por eso, ahora la chonta Quiri es bien alta y es difícil sacar sus frutos, no podemos trepar porque ¿no ves que tiene espinas? Toda culpa del gallinazo que se limpió el ano en su tronco...” (2016: 48-52).

Durante la década de 2010-2020 se ha venido realizando la misma actividad. Iniciamos la actividad de comparar los contenidos bilingües de la narrativa asháninka recopiladas y escritas por diferentes autores nativos y no nativos ribereños. La versión bilingüe de los documentos literarios que se produjeron en esta década para el pueblo asháninka acrecientan el esfuerzo por visibilizar la 
escritura asháninka de manera física y digital; estos ayudan a nuestra investigación a cumplir con el objetivo de realizar el análisis correspondiente de comparación literaria de dos periodos 2000 - 2010 y 2010 - 2020.

Por ejemplo, Solari (2020) en la tesis Aspectos de la deixis espacial en la lengua asháninka del Alto Perené menciona la forma de narrar recopilada en la frase narrativa oral de entrada como: "Iroñaaka sheetenika nonkinkitsatakoteri aparoni ashaninka ikantaitziri Apiinka", que tiene un significado literal de: "Ahora en esta tarde, voy a contarles sobre una persona llamada Apiinka" (2020: 83). Simultáneamente, el autor no presenta la frase de finalización, una frase de salida de los cuentos, relatos míticos que se narran; esto puede estar de acuerdo con sus objetivos planteados en su investigación, lo cual evidencia nuestra aseveración.

Los autores ucayalinos Huamán Almirón y Gómez Landeo (2018), en su documento literario Literatura Indígena Amazónica recopilan y muestran la narrativa oral de los pueblos jíbaros, panos y arawak sobre la forma de cómo se inicia una narración. Aquí presentamos el texto: "Aani charine Chaanari, sheripiari ini isaike Keshikisati, inampitaro Mañariniki itsipatari ishéninka”, que se traduce como "El abuelo Chaanari, fue un gran curandero que habitó las montañas del Gran Pajonal, en el lugar de Mañarini con su familia”. En el caso de la frase de salida o al finalizar la forma de narrar su estructura es como sigue: "Chaanita opoñari ñaantsi tsanaro irotake ikantantaitarori Chaanaro ikantantaitarori ashitarori Pitoka intamisato oshoke antamimashiki”, que se traduce como: "Chaanita proviene de la palabra Tsanáro y más sutil se dice Chaanaro que significa dueño de la Pituca silvestre que es fina y crece en el monte virgen" (2018: 123-126).

El escritor y recopilador asháninka Almonacid Leya (2015), en su libro Relatos orales asháninka presenta el contenido de la forma de narrar, el inicio de un hablante asháninka que comienza a realizar un discurso narrativo de la siguiente manera: "Timatsi sheripiari itasheake, ineake anta ibarentishiteki osheki parenti kitekabibeya", su significado en español es: "Había una vez un curandero que tenía mucha hambre. Solo tenía plátanos en su chacra, cuyos frutos ya estaban por amarillear". En esa misma forma, cuando el hablante culmina su cuento lo puede decir de esta forma: "Irosati ipiyaja sheripiari anta inampiki, tekatsibetanaji”, cuya la versión española es: "El curandero regresó a su casa, le pasó el efecto de la ayahuasca, amaneció y fue un día alegre y muy tranquilo" (2015: 34-38). 
La autora Mihas (2014) presenta en su libro Upper Perené Arawak Narratives of History, Landscape, and Ritual unos contenidos narrativos orales clasificados de historia, paisajes, y rituales del pueblo ashéninka cuya forma de narrar se asemeja a las demás investigaciones que inician con la frase de entrada: "Pikimavakina, noñaavintakotero okantavitani paisatziteni, tsika ipoñaaka ovakira ipokayetapaki yookantapakairi pairani virakochapaye"; en la traducción significa lo siguiente: "Me escucharás: voy a hablar de cómo vivían nuestros antepasados y luego de dónde vino el combate, considerando que fueron echados por los blancos" (2014: 51-53).

Rojas Zolezzi (2014), en su trabajo El morral del colibrínos muestra diversas formas de narración de los textos míticos asháninka. El hablante que narra nos dice: "Nokenkitsatakoteri Aroshi. Nonkenkitsateri ikantari Aroshi ishiyapitsatari", que significa: "Yo voy a contar del aroshi. Yo voy a contar lo que dicen de Aroshi que se escapó". Sin embargo, la frase de salida es muy precisa, se puede leer sintéticamente como: "Otsonkapaka" que significa "Terminó” (Rojas Zolezzi 2014: 349-354).

La autora Mihas (2011) en su libro Iñaani Katonkosatzi Parenini. El Idioma del Alto Perené recopila diversos cuentos, relatos, historias míticas y explicativa que nos acerca a analizar las formas narrativas que tienen los ashéninka. La frase de inicio: "Iroñaaka sheteenika nonkinkitsatakoteri aparoni asháninka ikantaitziri Apiinka", se traduce como: "Ahora en esta tarde, voy a contarles sobre una persona llamada Apiinka". Previamente a la frase de inicio hay un saludo de agradecimiento que el narrador realiza a su gente que se encuentra en el mismo lugar que él. La frase de salida de este cuento es así: "Ari okaratzi, akimakoventziri iroka Apiinka ikanta pairani. Pasonki”. Entonces, se puede traducir la frase como: "Así es, como hemos escuchado sobre este sucesor de inca, como era antes aquí. Gracias" (2011: 2-4).

Los autores Macera y Casanto (2009), en su libro titulado El poder libre asháninca demuestra diversos ejemplos de cómo se narra. Por ejemplo, de sus relatos míticos, exponemos este contenido de cómo se inicia la forma de narrar: "Yoca antariite obayeri Pishiro, yobaacoitziri viracochaqui iriitaque iyaaniini openpe ipotsota quisari, quiteriri opoñaa quityoncari. Iriitaque irisari yoca antariiteca obayeri Pishiyo cantzirori imanatziro chacopipaye"; llegando a la traducción de la frase con este significado explicativo: "Este gran guerrero Pishiro, traducido al castellano es pequeño tucán de color negro, amarillo y rojo. Era nieto del gran guerrero Pishiyo que dominaba el manejo de las flechas". 
Así pues, en la fase de culminación de la narración, tenemos esta frase de salida: "Tema irootaque obayeripayeca ipiantacariri aparoni cantashiyetachari pishitzi", con su significado siguiente: "Por eso estos guerreros lo convirtieron en una especie de tucancillo" (2009: 186-236).

El autor Anderson (2002) en sus recopilaciones de Cuentos folklóricos de los ashéninca de los años 1985-1986, con tres tomos de literatura oral, tiene diferentes ejemplos de cómo se inicia la narración oral en ashéninka, como se expresa en este ejemplo: "Pairani ametyo eeniro atziriveetani oshequi ametaro oquiricavaitzi. Iro cantzimaitacha pashinepayeeni cooya te iyotero iroori. Apaniroini osaicavaitzi iroori ametyo opancoqui oquiricavaitzi”; que ha sido traducido por Alberto Pablo Ravírez cuyo significado se lee: "Antiguamente, cuando la araña ametyo era persona, acostumbraba hilar todos los días. Las otras mujeres no sabían hilar. Ella estaba sola en su casa hilando. Así es el cuento de la araña Ametyo; cuando era persona le gustaba hilar" (2002: 206-207).

\section{Recursos de literatura y tradición oral en el contexto}

Al hablar de recursos literarios de tradición oral nos encontramos con diversos elementos de este canon literario como conceptualizaciones epistémicas de relato, cuento, mito, tradición, narrativa, memoria colectiva, relato mítico, conocimiento colectivo, revitalización lingüística, etc. A continuación, presentamos las definiciones que nos ayudarán a definir nuestro análisis y propuesta de investigación:

- Conocimiento colectivo. Son conocimientos (desarrollados, acumulados) que generan los pueblos o comunidades indígenas u originarios en correspondencia sobre la vida, la salud, la economía, el medio ambiente, las prácticas de construcción, la crianza y el manejo ambiental, la producción, el arte, la astronomía, etc., que se transmiten de generación en generación. (Decreto Supremo No 004-2016-MC).

- Cuento. Es una narrativa breve, oral o escrita, en la que se detalla una historia de cosas imaginadas con un reducido número de personajes. (Vírhuez 2010).

- Mito. Es un conjunto de creencias e imágenes idealizadas que se forma alrededor de un personaje o fenómeno (forma simbólica de las fuerzas de la naturaleza a aspectos de la condición humana) y que se convierte en un modelo o prototipo. (Espino 2015). 
- Narrativa. Es la habilidad o destreza de narrar las cosas. Además, es un género literario moderno conformado por la novela corta y el cuento. Es un conjunto de obras literarias escritas en prosa, como novelas o cuentos de un determinado autor, época o lugar. (Espino 2015).

- Relato. Es la acción de relatar algo breve detalladamente. (Vírhuez 2010).

- Relato mítico. Es un relato algo breve detallado de contenido mítico. Se trata de relatos cuyo contenido es mítico. La diferencia en su forma, tema y mensaje es dada por el contenido mítico, la habilidad del narrador oral y las costumbres tradicionales y vigentes en el acto de narrar. El acto narrativo de un integrante o comunero de una comunidad hacia su mismo pueblo es en realidad un pedazo o fracción de una narración continua (de larga duración) cuyos eventos, protagonistas y terminaciones no siempre coinciden pero guardarían una inexplicable incoherencia. (Vírhuez 2010).

- Revitalización lingüística. Es el proceso de detener o revertir la disminución de los hablantes de una lengua vigente en proceso de extinción catalogado como 'peligro o seriamente en peligro de desaparición' fomentando y fortaleciendo su uso. (Decreto Supremo No 004-2016-MC).

- Tradición. Es la transmisión o comunicación de noticias, literatura popular, doctrinas, ritos, costumbres, etc., que se mantiene de generación en generación. (Espino 2015)

- Tradición oral. Son todas las expresiones culturales de un grupo humano, cuyo vehículo de transmisión es la lengua oral. Este conjunto incluye los acervos de saberes y conocimientos colectivos de un pueblo o comunidad. (Decreto Supremo Nº04-2016-MC).

- Traducción directa. Es el proceso de interpretación que se realiza de otra lengua oficial (lengua indígena, Castellano o lengua extranjera) a la lengua materna del traductor. (Decreto Supremo Nº04-2016-MC).

- Traducción inversa. Es el proceso de interpretación que se realiza de la lengua materna del traductor a otra lengua oficial (lengua indígena, Castellano o lengua extranjera). (Decreto Supremo Nº04-2016-MC).

- Variedad lingüística o variedad de una lengua. Es el modo particular en que los hablantes de una comunidad usan para expresarse en diferentes formas orales en una lengua. Habitualmente, las diferentes variedades de una 
lengua no impiden el entendimiento entre hablantes de comunidades diversas. (Decreto Supremo N 004-2016-MC).

Además, en la zona de Junín, donde se centra la mayor población de hablantes asháninka, carecen de este repositorio. Además de ello, en las comunidades asháninka no se cuentan con bibliotecas comunales. En ese contexto postulamos que la tradición oral asháninka sea trabajada desde los propios interlocutores en la lengua, a la vez van interpretando la semanticidad de la lengua. De allí la necesidad de adecuar nuestro protocolo de trabajo a criterios contemporáneo. Es en esa línea, el grupo de investigación EILA-UNMSM, que participa del programa de posgrado de Letras, en la maestría en Educación Intercultural Bilingüe, un colectivo importante de colegas asháninkas participa con integrantes de nuestro grupo y se ha desarrollado una recopilación de tradición oral, especialmente de narrativa asháninka. Este insumo de relatos míticos orales, con los que contamos, desde la perspectiva indígena garantiza producción-innovación de estos contenidos en documentos virtuales (software) y físicos (libros de lectura) para las escuelas bilingües asháninkas y su tratamiento para los usos pedagógicos en el aula virtual y en la escuela rural.

\section{Metodología}

La investigación que presentamos es de tipo descriptivo-explicativo. Los procedimientos usados para realizar el estudio de investigación se diferencian según las diversas etapas que se compone la pesquisa. Así, la propuesta se inicia con la documentación bibliográfica referente al tema. Seguidamente, se organizó un cuestionario sociolingüístico a fin de recopilar los datos referidos a la narrativa escrita en lengua asháninka. Luego, se ejecutó el trabajo de transcripción de las grabaciones narradas, entrevistas sociolingüística obtenidas. Brevemente, los procedimientos realizados fueron los siguientes:

a. Elaboración de un cuestionario sociolingüístico para llevar a cabo la entrevista en la zona de Selva Central (Chanchamayo-Satipo). El cuestionario utilizado para la recolección de datos se estructuró de acuerdo con las diferentes propuestas de narración en el ámbito literario y discursivo de los relatos míticos: Por ello, se requirió de una entrevista abierta que hiciera posible la documentación de pequeñas narraciones orales y escrita en las que el hablante asháninka manifieste los nombres de diferentes relatos míticos que conoce y recrea. 
b. Observación participante en Selva Central (Chanchamayo-Satipo). Mediante un rastreo cartográfico previo en el cual se puso en práctica el método de la observación participante se pudo constatar, en la dinámica misma de recorrer los lugares de acontecimientos o sucesos históricos en el pasado-presente, el uso de vocablos asháninkas cuyos referentes podían documentarse en una grabación posterior.

c. Entrevista a asháninka hablantes bilingües. Las entrevistas se llevaron a cabo en forma directa, en casos en los que los hablantes de asháninka narraban los relatos míticos. Sin embargo, esta no fue la única fuente de recolección de datos. También se cruzó la información obtenida con el registro de docentes bilingües asháninka que rinden cada dos años el examen de lengua originaria auspiciado por DIGEIBIRA.

d. Transcripción de grabaciones. La recolección de audios permitió que, posteriormente, se realicen transcripciones de las pequeñas narraciones explicitadas por los hablantes nativos de asháninka. Luego, se extrajo el conjunto de vocablos relativos a las narrativas literarias de la lengua asháninka, lo cual incluyó el procedimiento de las formas de narrar.

A continuación, se efectuará el análisis y la sistematización de los datos recopilados. En esta sección, se organizarán los datos léxicos de la narrativa asháninka. Reflexionará sobre la pedagogía indígena. Trabajar imágenes sobre las características que debiera tener un material educativo en el entorno indígena; por eso, se adquirirá un software para editar libros virtuales (bookmarks, ARDORA u otros), para poder elaborar los contenidos bilingües que contendrá nuestro libro digital y físico. Este material a la par se validará en contextos escuelas de Educación Intercultural Bilingüe (EIB).

\section{Objetivos}

\subsection{Objetivo General}

- Desarrollar un estudio sobre el narrar en asháninka como estrategias de las narrativas de la oralidad del río asociada a la pedagogía indígena.

\subsection{Objetivos Específicos}

- Reconocer y caracterizar los tipos de relatos asháninka vigentes obtenidos en la Selva Central con narradores indígenas y transcribirlas. 
- Normatizar la escritura asháninka de los relatos y traducirlos al castellano.

- Organizar y editar las producciones narrativas escritas con su traducción y colocarlas en redes académicas.

- Publicar un material de uso pedagógico en soporte virtual.

\section{Resultados y discusión de los mismos.}

Fueron los mayores quienes nos autorizaron acceder a su lengua y a su cultura, a sus tradiciones orales en las diferentes versiones como un recurso pedagógico que nos permita, bajo bases comunes, comprender los aspectos de los relatos míticos. Para la fase de análisis se ha tenido en cuenta diversas propuestas.

a. La propuesta de Weiss (1975) respecto a la narrativa de la tradición oral nos menciona que encontró y clasificó dos clases de mitos:

- Mitos cosmogónicos

- Mitos ejemplares-explicativos

b. La segunda propuesta de Vílchez Jiménez (2002) describe la narrativa oral y escrita que hace una clasificación de la narrativa asháninka así:

- Tradiciones de origen

- Tradiciones de transformaciones

- Tradiciones orales de Nabireri, el dios transformador

c. La tercera propuesta es de Vírhuez Villafane (2010) que se refiere a tres componentes de relatos míticos de clasificación:

- Cosmogónicas

- De origen

- Culturales

Entonces, los relatos míticos están en un proceso de estructuración literaria al que se les puede añadir las características de humorísticas, fantásticas, fábulas, históricas, sociales, costumbristas, etc.

Este es el panorama actual del narrar en asháninka: la oralidad del río y escuela. Su estado del arte nos caracteriza que la literatura asháninka a través de su narrativa crea y se recrea en su propia estructura interna y externa, largos y breves, orales o escritos. Por consiguiente, respecto a las propuestas de los tres autores respecto al tema de la tradición oral podemos decir que el tema en el análisis que venimos realizando, sospechamos que los docentes bilingües y 
monolingües no toman en cuenta en el desarrollo de sus clases de enseñanzaaprendizaje en la escuela.

La autora Vílchez Jiménez (2002) nos expresa en esta cita:

Para la formación de estas sociedades indígenas, sus acervos orales son elementos de gran importancia; a pesar de ello, sus saberes y conocimientos fueron despreciadas por la escuela. Si deseamos entender la lógica de los espacios culturales amazónicos, andinos y a "los otros" es imprescindible que se les tome en consideración. (2002: 194)

Efectivamente, si queremos conocer, rescatar y preservar los saberes y conocimientos de estos pueblos indígenas en diversos temas que es de nuestro interés, debemos incluirlos en nuestros proyectos de vida.

Mirando hacia un futuro cercano, podemos diseñar nuestra propia propuesta de investigación acorde a la realidad de la tradición oral de los cuentos indígenas denominado "relatos míticos".

\section{Relatos míticos cosmogónicos}

Explica la fase de transformación mediante el cual un ente (o algo) es dotado de cualidades humanas, dicho de otro modo, fue concedido de manera biológica, psicológica y de conducta. Se refiere a las narraciones de las relaciones humanizadas de los astros, el ser humano y el universo (origen del mundo).

\section{Relatos míticos culturales}

En su gran mayoría se describe la aparición de las técnicas que el hombre inventa para conquistar la naturaleza, como la agricultura, la pesca, las viviendas, etc.

\section{Relatos míticos de origen}

Se refiere a la creación de hombres o seres humanos. Además, en este tema se hace reseña a la creación de elementos vegetales.

\section{Relatos míticos de seres sobrenaturales}

Se refiere dar una explicación mediante un relato el origen de seres, cosas, técnicas o instituciones. 


\section{Relatos míticos de transformaciones}

Se refiere a la mutabilidad de las personas en su estado actual y que luego se transforma en animales.

\section{Relatos míticos ejemplares-explicativos}

Estos relatos no tienen una finalidad. Sirven para explicar mediante la ilustración la manera de como el cosmos funciona. El relato mítico ejemplar, traduce una formula subjuntiva: «una vez ocurrió $\mathrm{X}$, y el resultado fue Y».

La aparición de la escritura en el idioma campa con las frases escritas en textos de versión bilingüe fue en 1890. Desde esa época la escritura de la gramática campa o anti ha sufrido diversas modificaciones en su alfabeto.

La narrativa oral actual del pueblo asháninka está tratando de analizar diversos textos que tienen formas de estructura que explican el universo mítico fundamentado en sus relatos míticos. El modelo propuesto, analizaremos algunos relatos míticos que evidencian la estructura interna:

- Frases narrativas encontradas en textos

Aquemacoventziri apaani ashéninca / Akemakobentsiri apaani ashéninka Akemakobentiri apaani asháninka

- Composición de una frase narrativa 
Akemakobenti-ri, ro

Verb. Kemakobentaantsi. Gén. m., f.

Escuchar
Num. + Sust.

Adj. + Sust.
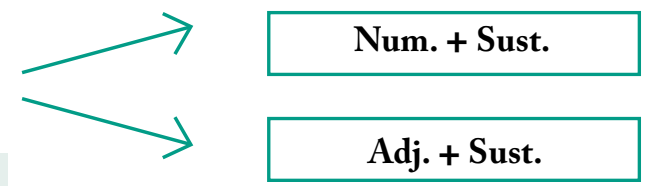

Escuchar

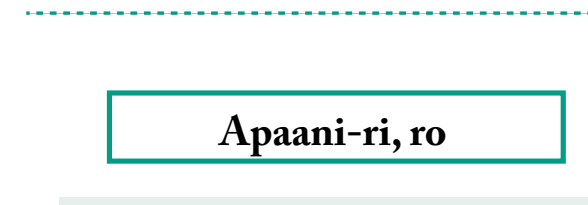

Num. Uno (a), Gén. m., f

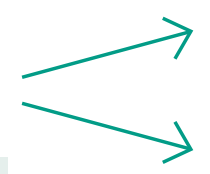

Sust. + Verb.

Algunos-(as)

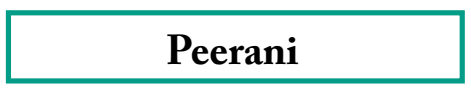

Adv. T. y L. Antes, hace tiempo

Antiguamente

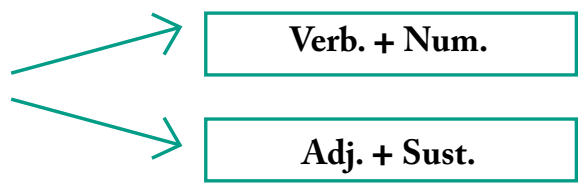

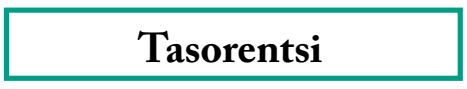

Sust. Dador de la vida

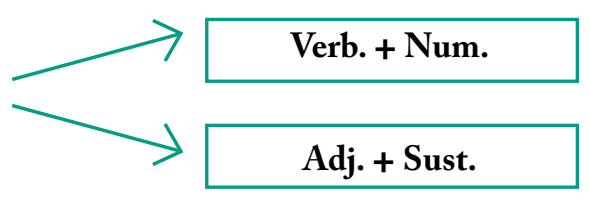

Dios asháninka

Como se puede notar, se tiene cuatro formas recurrentes de la frase narrativa que nos ayuda a corroborar nuestro estudio. 


\section{Analizando un texto}

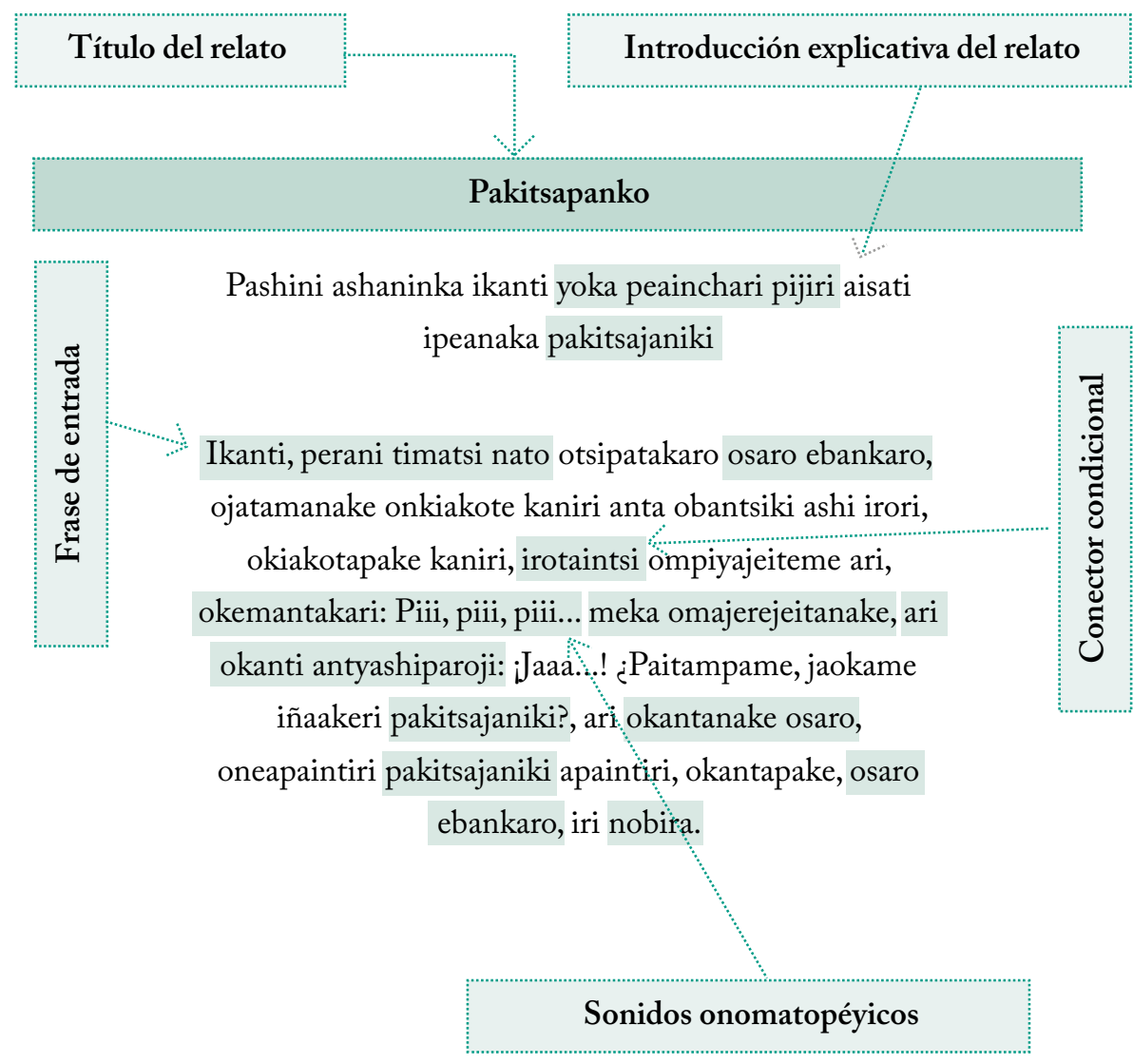




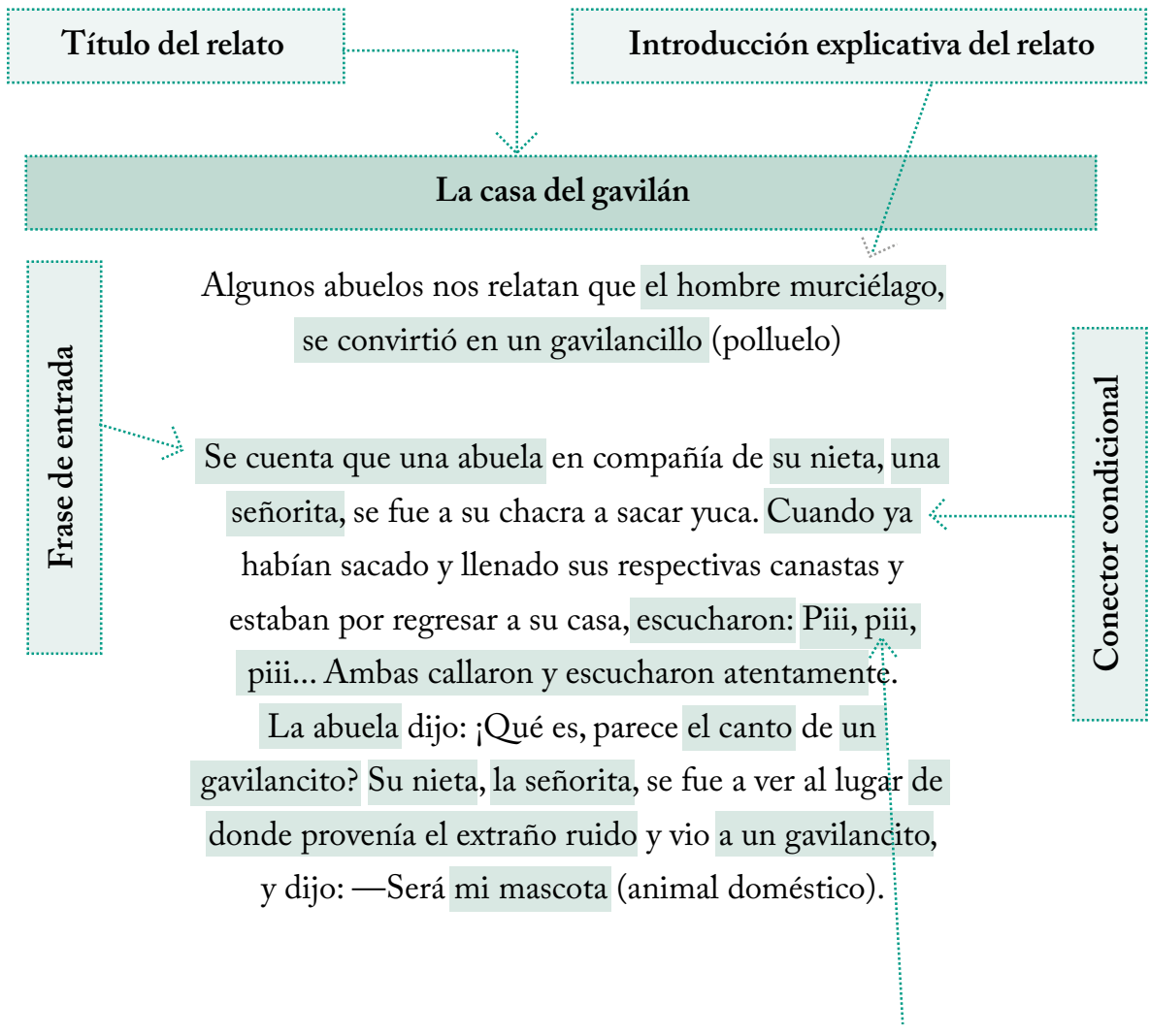

Sonidos onomatopéyicos 


\section{Frase de entrada recurrente}

Las frases de entrada de un relato mítico tienen esta forma:

Peerani eeniro jatsiribeetani etsi jiyotsiro ishobiritsi...

Peerani eeniro jatsiribeetani paro osheki ikashiyimaitachari irobaiteri...

Pairani eeniro jatsiribeetani pishitsi iriaani okanta itsoba....

Pairani eeniro jatsiribeta kobakitsi...

Apaani asháninka jiyaatake apaniroini irimaye irobaneki...

Apaani asháninka jiyaatsi jayi itsibine...

Apaani asháninka osheki jinebetaro iriaate otsishiki inkente osheto...

Apaani kitaite ari jiyobakeri apaani maini pankotsiki...

Apaani kitaite jatake iroñaaka irika asheninka paitachari pipina katonkonta...

Akemakobentsiri apaani asheninka itomintari...

Akemakobentsiri apaani asheninka osheki ishamebaitsi...

Akemakobentsiri apaani asheninka...

Timatsi apaani asheninka jaake iina...

Timatsi apaani asheninka jananenkanake amaityaake...

Timatsi apaani asheninka jiñiiri kamaari...

Timatsi apaani asheninka jiyaatake antamiki...

\section{Frase de salida}

Las más conocidas o frecuentes frase de salida de un relato mítico son:

Ari okaratsi / Ari okarati / Ari okarate / Ari okaratapai

Ari otsonka / Ari otsonkari / otsonkapaka / Ari othonkapakari

Ari okantari / Ari obirapakari kenkitsarentsi / Ari iro nokantiri 


\title{
Estructura interna de un relato mítico
}

Presentamos aquí nuestra propuesta de análisis que se realizó a los relatos míticos seleccionados de manera aleatoria:

\author{
Adverbio T y L + Adjetivo + Sustantivo \\ Adverbio T y L + Adverbio T + Verbo \\ Adverbio T y L + Negación + Verbo \\ Adverbio T y L + Pronombre demostrativo + Sustantivo \\ Adverbio T y L + Sustantivo + Negación \\ Adverbio T y L + Sustantivo + Verbo \\ Adverbio T y L + Verbo + Numeral \\ Adverbio T y L + Verbo + Numeral + Adjetivo + Sustantivo \\ Numeral + Sustantivo + Adjetivo \\ Numeral + Sustantivo + Sustantivo \\ Numeral + Sustantivo + Verbo \\ Verbo + Adjetivo + Sustantivo \\ Verbo + Adverbio T y L + Adverbio T \\ Verbo + Adverbio T y L + Sustantivo \\ Verbo + Numeral + Sustantivo \\ Verbo + Sustantivo + Adverbio $\mathrm{T}$
}

También podemos mencionar algunos elementos externos e internos que forman parte de la estructura literaria escrita como: anécdota (abishimotantsi), autor (sankenatirori), conector (obabiroñantsi), cuento (kenkitsarentsi), diálogo (kenkitsatabakantsi), introducción (nijantakotirori), investigar (asampitakoyete), lengua de los relatos (ñanentsi kenketsatakorentsipe), leyenda, fábula, mito, novela (okantakotiri), onomatopeya (poimatsatantsi), párrafo (okarakipana), relato, cuento, texto narrativo (kenkitsarentsi), recopilar (aye), resumen (orijanitakore), 
rima (apiapitachari ñantsi), texto (ñanarentsi), texto narrativo (kenkitsarentsi), título (osankenaitoki), tradición de los ancianos (intakaroniri).

\section{Conclusiones}

En esta investigación llegamos a algunas conclusiones a priori de acuerdo a nuestro estudio:

- Un relato mítico invoca un conjunto complejo de posibilidades que dialogan con el oyente (lector), lo que llevaría al investigador a no obviarlas (tradición oral, narrativa escrita, memoria colectiva, relato mítico, conocimiento colectivo, revitalización lingüística, traducción directa e inversa, variedad lingüística de una lengua, etc.).

- Las frases narrativas escritas, la frase de entrada y la forma de composición que se ha encontrado en textos son como sigue: akemakobetiri, ro; peerani, apaani-ri, ro; Tasorentsi, timatsi, etc.

- Las frases de salida o de culminación más frecuentes son:-Ari okaratsi / Ari okarati / Ari okarate / Ari okaratapai - Ari otsonka / Ari otsonkari / otsonkapaka / Ari othonkapakari - Ari okantari / Ari obirapakari kenkitsarentsi / Ari iro nokantiri.

- Los tipos de relatos míticos encontrados son: cosmogónicos, culturales, de origen, de seres sobrenaturales, de transformación, ejemplares-explicativos.

- La estructura interna de un relato mítico es como sigue: - Adverbio de Ty L + Adjetivo + Sustantivo; - Adverbio T y L + Adverbio T + Verbo; - Adverbio T y L + Negación + Verbo; - Numeral + Sustantivo + Adjetivo; - Verbo + Adjetivo + Sustantivo; - Verbo + Numeral + Sustantivo, etc. 


\section{Referencias bibliográficas}

Almonacid, Leo. Relatos orales ashaninka. Recopilación, investigación y traducción de Leo Almanocid Leya. Lima, Perú: MINEDU-DIGEIBIRA, 2015.

Anderson, Ronald. Historia de cambios de los ashéninka. Lima: Instituto Lingüístico de Verano, 2002.

Biagio, D'Angelo y María. Un río de palabras. Estudios sobre literatura y cultura de la Amazonía. Lima, Perú: Fondo Editorial de la Universidad Católica Sedes Sapientiae, 2007.

Espino, Gonzalo. Literatura oral, literatura de la tradición oral (Tercera ed.). Lima: Pakarina Ediciones, 2015.

Espinosa, Óscar. Los pueblos ashaninka, kakinte, nomatsigenga y yanesha. Serie Nuestros pueblos indígenas $\mathrm{N}^{\circ}$ 1. Lima: Lucent Perú, 2014.

Huamán, Abraham y Ángel Gómez. H. Literatura Indígena Amazónica. Yarinacocha, Pucallpa: Global Celtimweb E.I.R.L, 2018.

Jacinto, Pablo. Estudio del Sistema de Denominación Antroponímica de la Cultura Asháninka. Tesis para optar el Título de Licenciado en Lingüística, Facultad de Letras y Ciencias Humanas. Universidad Nacional Mayor de San Marcos. Perú: 2009.

Macera, Pablo y Enrique Casanto. El poder libre asháninca. Lima, Perú: Universidad San Martín de Porres, 2009.

Mihas, Elena. Añaani Katonkosatzi Parenini. El idioma del Alto Perené. London, United States of America: University of London, 2011.

Mihas, Elena. Upper Perené Arawak Narratives of History, Landscape, and Ritual. United States of America: University of Nebraska Press, 2014.

MINEDU. Diccionario escolar Asháninka/Ashéninka. Lima, Perú: FORTEPE/PROEBI, 2000.

Rojas, Enrique. El morral del colibrí. Mitología, chamanismo y ecología simbólica entre los Ashaninka del Oriente peruano. Lima, Perú: Horizonte, 2014.

Solari, Óscar. Etnosemántica de los colores en la lengua asháninka una visión cognitiva, sincrónica y diacrónica. Tesis para optar grado de Magíster en Lingüística. Unidad de Posgrado, Facultad de Letras y Ciencias Humanas. Universidad Nacional Mayor de San Marcos. Lima: 2019. 
Solari, Óscar. Aspectos de la deixis espacial en la lengua asháninka del Alto Perené. Tesis para el título profesional de Licenciado en Lingüística. Escuela Profesional de Lingüística, Facultad de Letras y Ciencias Humanas. Universidad Nacional Mayor de San Marcos. Lima: 2020.

Toro, César. "Mitología amazónica. Estudio de aproximación desde la diversidad de mitos, leyendas, cuentos maravillosos, mitólogos y compiladores orales de la Amazonia". En D. Biagio y M. A. Pereira, Un río de palabras. Estudios sobre literatura y cultura de la Amazonia. Lima, Perú: Fondo Editorial de la Universidad Católica Sedes Sapientiae, 2007, 49-88. .

Vílchez, Elsa. "La tradición oral entre los Ashaninkas y los Matsigengas de la Amazonía Peruana”. En G. Espino Relucé, Tradicion oral, culturas peruanas: una invitación al debate. Lima, Perú: Fondo Editorial Universidad Nacional Mayor de San Marcos. 2002, 191-199.

Virhuez, Ricardo. Letras indígenas de la Amazonía Peruana (Segunda ed.). Lima: Pasacalle E.I.R.L., 2010.

Vírhuez, Ricardo y Johnny Yapo y Aliza Yanes. Seres fantásticos del Perú. Lima, Perú: Pasacalle, 2014.

Weiss, Gerald. Campa Cosmology (Vol. 52). New York, EEUU: The American Museum of Natural History, 1975.

Yangali, Jorge. Enteogonia de los Pueblos Originarios de la Selva Central Peruana en su Literatura Oral. Huancayo, Perú: Grapex Perú S.R.L., 2016. 